\title{
Moderating Role of Teachers' Academic Support between Students' Satisfaction with Online Learning and Academic Motivation in Undergraduate Students during COVID-19
}

\author{
Sabila Naseer (D) and Shamim Rafique (D) \\ University of the Punjab, Lahore, Pakistan \\ Correspondence should be addressed to Sabila Naseer; sabilanaseerpu@gmail.com and Shamim Rafique; shamimrafique.fh@ \\ gmail.com
}

Received 22 June 2021; Accepted 7 October 2021; Published 2 November 2021

Academic Editor: Ehsan Namaziandost

Copyright @ 2021 Sabila Naseer and Shamim Rafique. This is an open access article distributed under the Creative Commons Attribution License, which permits unrestricted use, distribution, and reproduction in any medium, provided the original work is properly cited.

\begin{abstract}
The study explored the moderating role of teachers' academic support between students' satisfaction with online learning and academic motivation during the pandemic of COVID-19 in Pakistan. It was hypothesized that teachers' academic support is likely to moderate the relationship between students' satisfaction with online learning and the academic motivation of undergraduate students. A correlational research design was used and a sample of 406 students (male and female) within the age ranges of 18-22 years $(M=21.09, \mathrm{SD}=1.41$ (male); $M=20.18, \mathrm{SD}=0.71$ (female)) were included. The sample was selected through the purposive sampling strategy from different universities in Punjab, Pakistan. Students' Satisfaction with Online Learning Questionnaire, Teachers' Academic Support Scale, and Academic Motivation Scale were used. The results of moderation analysis through PROCESS macro 3.5 revealed that teachers' academic support played a moderating role in students' satisfaction with online learning and the academic motivation of undergraduate students. Findings will provide support to educational administrators, policymakers, course designers, and curriculum developers for organizing the curriculum and formulating a system to identify that students need different support optimally in a digital learning environment.
\end{abstract}

\section{Introduction}

COVID-19 is a novel coronavirus and it has spread across the globe. During the shutdown phase in Pakistan, all educational institutions stopped presence teaching and had to turn the education system into digital instruction [1]. Academic activities were functionally declined [2]. At the beginning of February 2020, only China along with few other infected countries closed their institutions. Later on, by the middle of March, approximately 75 countries shut down their educational institutions due to this proliferating contamination. According to UNESCO, by the end of April 2020, about 186 countries closed their institutions because $73.8 \%$ of learners of the total enrolled students were infected [3]. Although the lockdown and social distancing were the only solutions to break the chain of the transmission of this
COVID-19 pandemic, due to the shutdown of educational institutions, the learning rate was badly affected. As in some countries, the institutions were closed for an indefinite period. The administration of the schools, colleges, and universities with the help of government policies made experiments to find out ways to complete the approved syllabus of the students within the predetermined time frame by remaining in line with the academic calendar [4].

Many countries turned their education system into digital instruction. Digital learning or E-Learning is also known as electronic or online learning. Knowledge is acquired through media and electronic technologies and conducted through the internet [5]. Students can get material by using Google Classroom, Meet, Zoom, Blackboards, Microsoft Teams, WhatsApp, and other platforms to sustain the learning process. But the question is about the 
preparation, designing, and effectiveness of E-learning. Pakistan is an underdeveloping country where the concept of digital instructions or E-learning is not plainly understood because of facing technical constraints, and issues in the online interface, lack of suitability of Internet devices, and availability of other online resources were the biggest challenges [6]. However, the online learning mode has impelled innovations with the help of digital interventions. These experiments were a light in the dark clouds with the slow pace of reforms in academic institutions all over the world. With the efforts of educational institutions, the learning process was continued without any gap in such COVID-19 pandemic. But it is significantly explored that the quality of the online-learning process depends upon digital efficiency and access. Access is possible with proper instructions and the guidance of teachers. Learning in a traditional classroom in front of the instructor and online mode is intensely different. The students' academic satisfaction, interaction with the instructor, and motivation are very important in E-learning [7]. Instructors' interaction and teachers' academic support always strengthen all kinds of behaviors of students related to education as teachers' support successfully moderated the effect of stress on externalizing problems explored by Huber et al. [8]. Garrison et al. [9] proposed that a convenient intervention of online learning and teaching is offered by the Community of Inquiry (COI). According to the Community of Inquiry team, a learner's group is created to determine the success of webbased instructions. In this group, learning occurs by three mutually supported components as social presence, cognitive presence, and teachers' presence. In recent studies, teachers' presence and relationship with students and its effect on classroom learning have remained a major concern [10-12].

In Pakistan, a transition of online classes has been initiated whenever the Government announced a nationwide lockdown. All the educational institutions tried to enhance the quality of learning of the students. Their main focus was how the suitable content can be organized and executed through virtual mode and how the students' issues which they are facing can be removed [13]. Online classes indeed are the best substitute for physical classes in different pandemic situations if these are designed appropriately. Adams and Umbach [14] claimed in their research that no significant difference in satisfaction is found between online learning and traditional classroom learning, but the condition is to arrange online classes properly. These facts clearly showed us that online learning is inevitable in different pandemic situations if suitably designed training sessions for students are arranged by the trainers and instructors.

The research is more applicable in the present situation of Pakistan, where students are facing several constraints and confused in both online and physical instructions. In such circumstances, students' satisfaction with their online learning process is the main target. Academic satisfaction level is the students' overall evaluation and psychological state about their educational experiences and the expectations which they have about their educational system [15].
Advancement in technology regardless of facing all the challenges helps us to implement and plan the content in multiple ways for E-learning. Faculty members of any educational institution may contribute by guiding the students about digital learning too, which enhances their motivation towards such academic setup [16]. Students' satisfaction and positive perception about the learning process are very important for the readiness and motivation of the students. As motivation is the most significant phenomenon particularly for university students in the realm of education, it is a force that energizes individuals towards their goals. Selfdetermination theory, one of the motivation theories, deals with the degree of how the individuals are self-determined and self-motivated towards a desired goal [17]. This theory compared intrinsic motivation to extrinsic motivation. So, teachers' academic support can be worked as an extrinsic motivator, while their level of satisfaction enhances the intrinsic motivation which is more important than extrinsic motivation to accomplish the goals in the area of education $[18,19]$. Warner et al. [20] described the concept of mental readiness for online learning in the vocational education and training sector in Australia and argued E-learning readiness in the form of three main aspects. The first one is the students' preference about the way by which content is delivered as compared to traditional classrooms. Secondly, the student's confidence is very important for familiarity and utilizing electronic devices. Their competence for Internet and online communication is very concerned; and the third is their capability to engage themselves in independent learning. Administration and instructors play a significant role in all kinds of learning. This concept was further investigated by numerous studies. McVay $[21,22]$ developed a measure of 13 items for evaluating the students' attitude and behavior as predictors of online classes.

Another study explored the validity of McVay's instrument (2000) for online willingness and concluded with two factors: "comfort with e-learning" and "self-management of learning" [23]. Subsequently, several studies were conducted for further defining and operationally using the concept of mental readiness, satisfaction, teachers' support, and motivation for online learning [23]. The factors which motivate the students for online learning were students' satisfaction with the delivered process and content, instructor's educational support and self-directed learning $[21,22,24]$, motivation for learning $[17,25-27]$, and online communication self-efficacy [21,28]. The instructor's interaction and facilitation are also very important for students' satisfaction and positive perception of online learning. Students' characteristics are also very important in their motivation as students' age, gender, major subjects, and GPA are significantly correlated with the motivation and performance of the students [29]. These factors have been explored in several studies. The healthy interaction with the instructor and his/her academic support produces critical thinking among the students [30-32]. Multiple studies also revealed the strengths and weaknesses of online learning. Both students' and teachers' competence and capability to use the technology represent the strength of online learning which enhances the students' satisfaction [33]. 
Well-prepared course content and well-structured curriculum, instructor's instructions, feedback and clear way to deliver content, and demographic factors like age, gender, and academic background are also very effective in digital learning $[34,35,36]$. However, both strengths and weaknesses have been also identified in the literature. Students' dissatisfaction and feelings of isolation, noncooperative behavior of teachers, very slow response rate, instructors' related issues, electricity problems, technical issues, Internet connectivity barriers, need for commitment for online learning, discipline, and planning, and high rate of students' attrition are the main constraints of online learning [37-43]. In a few studies, findings indicated that there is no significant difference in students' attitude, satisfaction, and motivation between online learning and traditional learning [44]. The students' output can be more satisfactory if the online learning can be facilitated by the instructors and organized more appropriately [45].

However, by evaluating the previous literature, students' satisfaction and teachers' academic support have a major contribution to enhancing the academic motivation of the students. Particularly teachers' academic support strengthens the relationship between satisfaction of the students and academic motivation [30-32]. So, the current study highlighted a hypothetical model that depicts the moderating role of instructor's support in academic activities between students' satisfaction and academic motivation along with few demographics. The study also highlighted the barriers and level of satisfaction of the learners regarding online learning during this COVID-19 pandemic and how their satisfaction leads to their academic motivation. On the basis of the previous researches, a hypothesized model was designed for the current study which shows the hypothesized relationship between the study variables in Figure 1.

Both favorable and unfavorable feedback regarding online classes of the students would help the policymakers, curriculum developers, and educational administration to provide an effective platform for learning. The findings of the study would be fruitful for all kinds of subjects due to two main reasons. Firstly, online mode for learning was sudden to control COVID-19. Educational institutions have no abrupt strategy and policy for organizing and implementing the course content in an online platform. This can deliver and fulfill students' academic and learning needs in a productive, effective, and simple way. Secondly, long-term policy cannot be generated because no certain shreds of evidence are found about when this pandemic will be over or what kind of life will be after this pandemic. The strategy must be applied in such a form that can fulfill the criteria of combination of online and offline classes [38].

\subsection{Hypotheses}

HI: There is likely to be a positive relationship between students' satisfaction with online learning, teachers' academic support, and academic motivation among undergraduate students during COVID-19.
HII: Teachers' academic support is likely to moderate the relationship between students' satisfaction with online learning and academic motivation among undergraduate students during COVID-19.

\section{Method}

2.1. Participants. The sample was comprised of 406 undergraduate students from different universities in Punjab. The purposive sampling strategy was used to collect the data as a specific criterion was chosen to select the participants that were mentioned in the participants' datasheet. Because the study has a particular purpose to seek online learning satisfaction, teachers' support, and their academic motivation in the current adopted learning process because of the pandemic, only those participants who fulfilled the following criteria were included.

\subsection{Inclusion Criteria}

(i) For comparing the study variables, both male and female students were included within the age range of 18-22 years

(ii) Only those students who were taking online classes due to this pandemic COVID-19 rather than those who were already engaged in distance learning programs were included

(iii) The students who had a minimum experience of two semesters of online classes due to this pandemic were included so that they could compare study variables with physical class learning

(iv) The students were included in the study from different universities of Punjab where the learning process was physical in normal routine

(v) The students from social, natural, and formal sciences were included in the study

\subsection{Exclusion Criteria}

(i) The students having some disability were excluded from the study, because the issues they were facing might be due to already because of their disability rather online in their learning process.

(ii) The participants who had some diagnosed psychological problem were also excluded, because such students are already psychologically weak and could not accept change quickly.

There were a total of 428 students in this study. 406 students were engaged in online learning from the last two semesters due to this pandemic, while the other 22 students were excluded due to engaging in distance learning education as well as having experience of online classes less than 2 semesters. They were undergraduate students within the age ranges of 18-22 years (male: $M=21.09, \mathrm{SD}=1.41$; female: $M=20.18$, $\mathrm{SD}=0.71)$ from different universities of Punjab. $161(39.5 \%)$ were male students, while 245 (60.5) were female students. The participants were from different faculties: social, 157 (38.67\%), natural, 188 (46.30\%), and formal sciences, 61 (15.03\%), as explained in Table 1 . The students who had some diagnosed 


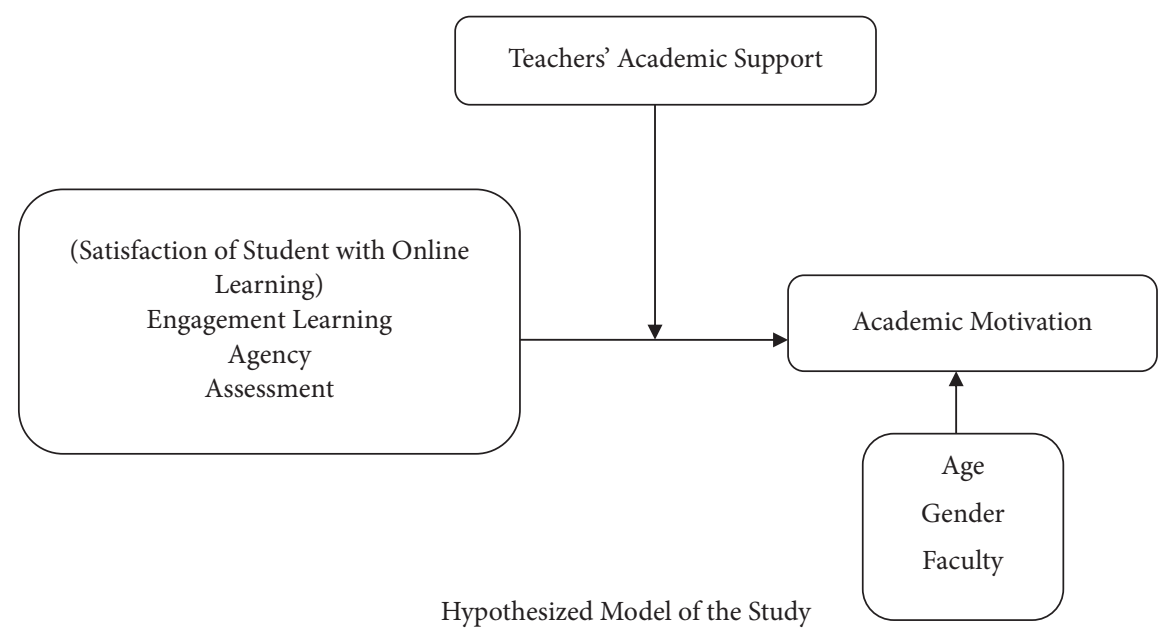

FIgURE 1: Hypothesized model of the study.

TABle 1: Descriptive statistics of demographic characteristics $(N=406)$.

\begin{tabular}{lcc}
\hline Characteristics & Male $f(\%)$ & Female $f(\%)$ \\
\hline Age (in years) $M(\mathrm{SD})$ & $21.09(1.41)$ & $20.18(0.71)$ \\
Gender & $161(39.5)$ & $245(60.5)$ \\
Faculty & & \\
Social sciences & $68(42.2)$ & $89(36.3)$ \\
Natural sciences & $57(35.4)$ & $131(53.5)$ \\
Formal sciences & $36(22.4)$ & $25(10.2)$ \\
\hline
\end{tabular}

physical or psychological problem were also excluded as mentioned in the demographics.

\subsection{Assessment Measures}

2.4.1. Student Satisfaction with Online Learning. For measuring the construct students' satisfaction with online learning, a scale with 16 items constructed by [46] was used. It is a 3point Likert scale (1-3) as satisfied, ambivalent, and dissatisfied. It has 3 subscales as engaged learning, agency, and assessment. This is a general scale used to measure the online learning satisfaction of the students. The sample items of engaged learning are "Generally, I understand course requirements better in an online course" and "I am more likely to ask questions in an online course." The items of the agency are "I am motivated to succeed" and "I have strong time management skills." The third subscale assessment has items as "Assessment of my academic progress is more accurate in online courses" as well as "Response time from teachers and assistants is quicker in online courses." The students were asked to fill the questionnaire keeping in mind the current learning process. Alpha reliability of the scale was 0.96 and subscales had engagement learning 0.86 , agency 0.60 , and assessment 0.77 reliability. The current reliability coefficient of the scale is 0.94 and its subscales have $0.81,0.73$, and 0.82 , respectively.

2.4.2. Teacher Academic Support (TAS) Scale. The construct was measured by the Teachers' academic support subscale of Classroom Life Measure [47]. The 4-item Teachers'
Academic Support Scale (Cronbach's $\alpha=.84$ ) asks about perceived support for learning, such as "My teachers like to help me learn." The current reliability is 0.40 .

2.4.3. Academic Motivation Scale. The academic motivation of the students was measured by the Academic Motivation Scale [48] with a bit of modification. It has 3 subscales containing 28 items. It is a 7-point Likert scale (definitely no $=1$ to definitely yes $=7$ ). The mean alpha value of the scale was 0.81 and subscales had extrinsic motivation, intrinsic motivation, and A motivation. All subscales had above 0.78 Cronbach's alpha reliability. Meanwhile, in the current study, the reliability coefficient is 0.82 and subscales have $0.76,0.78$, and 0.88 reliability, respectively. The overall questionnaire was used in the current study. The sample items are like "Because I experience pleasure and satisfaction while learning new things" and "Because I think that a university education will help me better prepare for the career I have chosen."

2.5. Procedure. Permission was taken for using the questionnaires from the concerned authors. Data was collected through Google form. The link was shared with the students and also consent to participate in the study was taken. Confidentiality and anonymity were maintained. A total of 428 participants participated in the study and submitted their questionnaires of which few were discarded and the response rate was $95 \%$. The data were analyzed by using IBM SPSS 22 and PROCESS macro 3.5 by using suitable analyses.

\section{Results}

The current study was conducted to seek the level of satisfaction among the undergraduate students and its relationship with the academic motivation of the learners during the COVID-19 pandemic. The moderating role of teachers' academic support between students' satisfaction with online learning and academic motivation was also investigated. Pearson Product Moment correlation was run to find out the 
relationship between demographic variables, student satisfaction with online learning, and academic motivation.

The findings of Table 2 indicated that the students' satisfaction about engagement learning (willingness of taking online courses), agency (motivation, time management skills, and multitasking ability), assessment (evaluation process), the overall level of satisfaction with online learning, and teachers' academic support are significantly positively correlated with the academic motivation of the students.

To test the hypothesis that teachers' academic support would moderate the relationship of students' satisfaction with online learning and academic motivation, the PROCESS macro approach was used [49], to run the analysis and to compute the interaction terms.

The assumptions of normality, linearity, homoscedasticity, and multicollinearity were tested before the moderation analysis for the variables. The findings are given below.

The results of Table 3 revealed that the model testing the main effects of age (covariate), students' satisfaction with online learning, and teachers' academic support was significant $\left(R^{2}=.56, F(4,401)=30.75,<0.001\right)$. As shown in Table 2, the main effects of age (covariate) and teachers' academic support were significant in predicting academic motivation among undergraduate students. The moderating effect of students' satisfaction with online learning was significant on the relationship between students' satisfaction with online learning and academic motivation among undergraduate students.

Figure 2 shows that the interaction effect of students' satisfaction with online learning and teachers' support on academic motivation among undergraduate students is not significant on all levels because the academic motivation is parallel on all levels of the moderator.

The findings of Table 4 revealed that $35 \%$ of students were dissatisfied, $27.3 \%$ were ambivalent, and $37.7 \%$ were satisfied with their online learning. In engagement learning (willingness of taking an online course), 25.9\% of students were dissatisfied, $33.7 \%$ were ambivalent, and $40.4 \%$ were satisfied. Further $31.5 \%$ of students were dissatisfied, $30.8 \%$ were ambivalent, and $37.7 \%$ were satisfied in agency (motivation, time management skills, and multitasking ability). In the assessment (evaluation process) of line classes, $47 \%$ of students were dissatisfied, $21.9 \%$ were ambivalent, and $31 \%$ were satisfied. Overall the students are more satisfied with engagement learning and agency while less satisfied with the evaluation system of online learning.

Figure 3 indicates that male students were $32.3 \%$ dissatisfied. $28 \%$ were ambivalent and $39.8 \%$ were satisfied with their online learning process. Additionally, $36.7 \%$ of female students also showed dissatisfaction, $26.9 \%$ were ambivalent and $36.4 \%$ revealed satisfaction with their online classes. Comparatively percentage of male students' satisfaction with online learning is higher than that of the female students.

\section{Discussion}

The primary concern was to investigate the moderating role of teachers' academic support between students' satisfaction with online learning and academic motivation of undergraduate students during the COVID-19 which has become a nightmare all over the world. All spheres of life have suffered from this pandemic including social, economic, and political as well as educational structures. Education is the most badly affected area. Advanced countries easily molded their physical education with the online system. On the other side, third-world countries like Pakistan are facing many challenges as faculties and teachers are neither well trained nor equipped with new technology [50]. In Pakistan, since the pandemic is spread, all the educational institutions are shut down and the educational setup has turned online. The study showed the important role of satisfaction of the students with their online learning process because it is a successful component in the environment of digital learning. Many of the respondents $(37.7 \%)$ to some extent were ready to deal with the challenges and were satisfied with the online learning, while $36 \%$ were dissatisfied and $27.3 \%$ had mixed attitudes as described in Table 4. Evaluating the students' perception and attitude for any innovation in academic setup is very important as early studies also provided primary insight into such prospects of the online learning process [51, 52]. If the students are satisfied with their learning, academic needs, and learning outcomes and receiving the guideline from their teachers, then this thing works more powerfully to enhance their motivation towards their education as claimed by Snopce and Alija [53]. The current findings are in line with the previous one, as when the students are more satisfied with online learning needs and engaged in the academic process with the help of their instructors, they are more motivated, as explained in Table 3, as interaction between teachers' support and students' satisfaction was found to significantly affect the academic motivation. Students' interactivity and engagement are an energizing force for the success of online learning [47]. Further Gunawardena and Zittle [54] revealed the positive correlation between learners' active presence in online classes and satisfaction. Similarly, the current findings also indicated the strongest link between engagement learning (students' willingness) for online learning and their motivation.

In Online learning, the students engage themselves in multiple creative activities, where they can utilize their abilities and learn to cope with the barrier with the help of their instructors as argued by [55]. In the same way, agency (ability and skills to manage the task) and teachers' academic support in current findings significantly correlate to the academic motivation of the students. This indicates a strong connection between both factors. Assessment is also a very significant segment of online learning. If the learners get intime answers to their queries from their instructors and are satisfied with their evaluation procedure, then they are more motivated for such learning process as also reported by Hara [56], Petrides [40], and Vonderwell [43]. These findings support the present study as if the learners are more engaged, more creative to deal with the challenges, and more mentally ready for an evaluation process of online learning, they are more satisfied. Further receiving guidance from their concerned faculty members also enhances their motivation for such innovation in academic setup [44, 57-59]. 
TABLE 2: Intercorrelation of students' satisfaction with online learning, teachers' academic support, and academic motivation of the undergraduate students $(N=406)$.

\begin{tabular}{|c|c|c|c|c|c|c|c|c|c|}
\hline Variables & 1 & 2 & 3 & 4 & 5 & 6 & 7 & 8 & 9 \\
\hline (1) Age & - & 0.06 & -0.02 & $-0.10^{*}$ & -0.03 & -0.03 & -0.08 & 0.09 & 0.07 \\
\hline (2) Gender & & - & -0.06 & -0.07 & 0.01 & 0.01 & -0.04 & 0.01 & -0.02 \\
\hline (3) Major Dep. & & & - & -0.04 & -0.10 & 0.06 & 0.11 & 0.09 & 0.08 \\
\hline (4) EL & & & & - & $0.85^{* * *}$ & $0.85^{* * *}$ & $0.97^{* * *}$ & $0.19^{* * *}$ & $0.55^{* * *}$ \\
\hline (5) Agency & & & & & - & $0.79^{* * *}$ & $0.92^{* * *}$ & $0.19^{* * *}$ & $0.52^{* * *}$ \\
\hline (6) Assessment & & & & & & - & $0.92^{* * *}$ & $0.19^{* * *}$ & $0.52^{* * *}$ \\
\hline (7) SOL Total & & & & & & & - & $0.20^{* * *}$ & $0.57^{* * *}$ \\
\hline (8) TAS & & & & & & & & - & $0.50^{* * *}$ \\
\hline (9) AM & & & & & & & & & - \\
\hline
\end{tabular}

Dep. $=$ department, $\mathrm{EL}=$ engagement learning, $\mathrm{SOL}$ Total $=$ satisfaction with online learning total, $\mathrm{TAS}=$ teachers' academic support, and $\mathrm{AM}=\mathrm{academic}$ motivation.

TABLE 3: Moderating effect of teachers' academic support on the relationship of students' satisfaction with online learning and academic motivation $(N=406)$.

\begin{tabular}{|c|c|c|c|c|c|}
\hline \multirow{3}{*}{ Variables } & \multicolumn{5}{|c|}{ Academic motivation } \\
\hline & \multirow{2}{*}{ B } & \multirow{2}{*}{$\mathrm{SE}$} & \multirow{2}{*}{$\mathrm{T}$} & \multicolumn{2}{|c|}{$95 \% \mathrm{CI}$} \\
\hline & & & & LL & UL \\
\hline \multicolumn{6}{|l|}{ Main effects } \\
\hline Age & $0.07^{*}$ & 0.04 & 1.99 & 0.01 & 0.14 \\
\hline SS & $0.69^{* * *}$ & 0.15 & 4.50 & 0.39 & 0.99 \\
\hline TAS & $0.82^{* * *}$ & 0.15 & 5.38 & 0.52 & 1.12 \\
\hline \multicolumn{6}{|c|}{ Interaction effect } \\
\hline SS xTAS & $0.05^{*}$ & 0.02 & -2.02 & -0.09 & -0.00 \\
\hline Total $R^{2}$ & $0.56^{*}$ & & & & \\
\hline
\end{tabular}

Note. ${ }^{* * *} p<0.001,{ }^{* *} p<0.01$, and ${ }^{*} p<0.05 . \mathrm{SS}=$ students' satisfaction and TAS $=$ teachers' academic support.

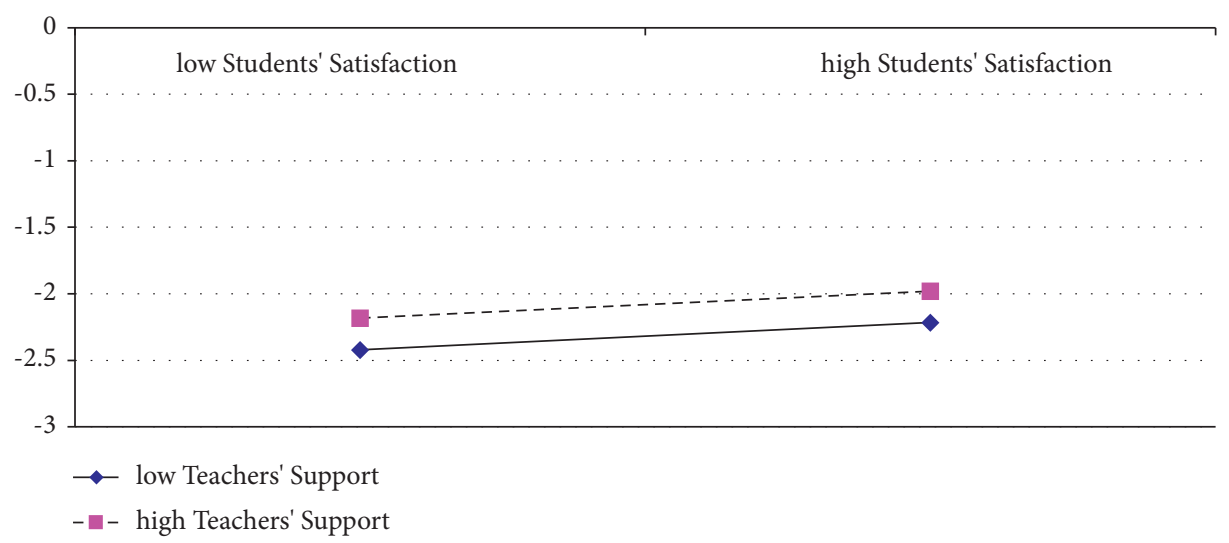

FIGURE 2: Interaction effect of students' satisfaction with online learning and teachers' academic support on the academic motivation among undergraduate students $(N=406)$.

The present findings strengthen this notion as teachers' support and students' satisfaction with their online learning experiences are the strongest predictors of academic motivation in such circumstances. Teachers' support was also found as a moderator between both study variables. The findings are consistent with previous literature, where perceived lecturer support was found as a significant moderator between academic self-efficacy and study engagement [60]. Association between teacher support and students' academic emotions was also explored by Lei et al. [61]. The results provided strong evidence that linking teacher support and students' academic emotions along with students' culture, age, and gender moderated these links. Although in the current study demographic characteristics are not significantly moderating the link between the study variables, teachers' support moderates the connection between students' satisfaction and academic motivation of the students. The students' percentages regarding being satisfied, dissatisfied, and ambivalent kind of level also help the administration to highlight the hindrances which are faced by the students in digital instructions. Online learning is a golden opportunity for all the students which is allowed by 
TABLE 4: Percentage of undergraduate students in general satisfaction, satisfaction in engagement learning, agency, and assessment of online learning $(N=406)$.

\begin{tabular}{|c|c|c|c|c|}
\hline Level of satisfaction & Overall satisfaction with online learning & Engagement learning & Agency & Assessment \\
\hline Dissatisfied & $142(35 \%)$ & $105(25.9 \%)$ & $128(31.5 \%)$ & $191(47 \%)$ \\
\hline Ambivalent & $111(27.3) \%$ & $137(33.7 \%)$ & $125(30.8 \%)$ & $89(21.9 \%)$ \\
\hline Satisfied & $153(37.7 \%)$ & $164(40.4 \%)$ & $153(37.7 \%)$ & $126(31 \%)$ \\
\hline
\end{tabular}

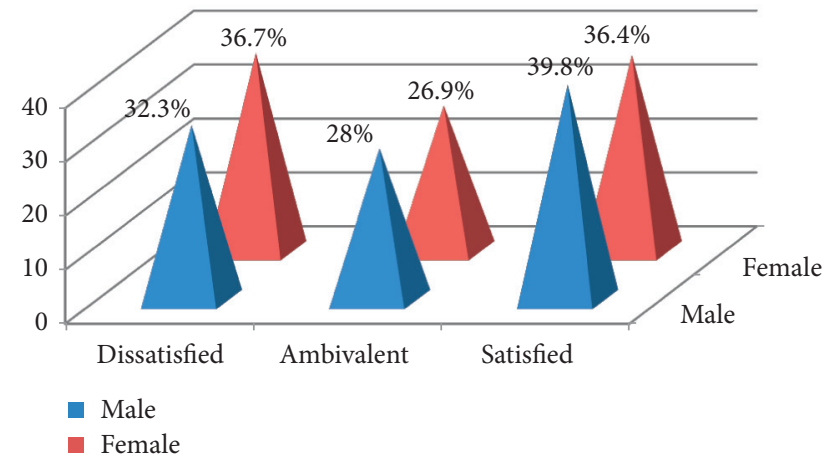

Figure 3: Percentage of general satisfaction of undergraduate students with online learning for male students $(n=160)$ and female students $(n=246)$.

different institutions, and learners' opinion is very important for promoting the strengths of such kind of learning as has been expressed in the current study.

\section{Conclusion}

The importance of teachers' academic support and students' satisfaction with their online learning was explored in the current time when the whole education system has altered into online and teachers' support has become very critical in suddenly adapted educational setup. The study contributed to the previous literature by highlighting the significant role of teachers' academic support between students' satisfaction with their learning experiences and their level of motivation in academic activities.

5.1. Recommendations for Future Studies. Further qualitative studies can be conducted throughout Pakistan (all provinces) for exploring the issues and challenges in the online learning process. Further participants' characteristics should be studied in upcoming studies. The current study is fruitful for making new policies, curriculum development, and designing an effective evaluation system for students in online mode so they can be satisfied and more energized towards their learning process in any urgent situation.

5.2. Implications of the Findings. The findings of the study are helpful for educational administrators, policymakers, course designers, and curriculum developers for organizing the whole online setup. Teachers' interaction and involvement not only online but also in traditional classrooms are very important for students' satisfaction and their learning motivation. So educational policies should be modified and teachers' roles should be maximized in the learning process for the success of the educational system.

\section{Data Availability}

All required data are provided within the article.

\section{Conflicts of Interest}

The authors declare that there are no conflicts of interest.

\section{References}

[1] S. Chandir, D. A. Siddiqi, M. Mehmood et al., "Impact of COVID-19 pandemic response on uptake of routine immunizations in Sindh, Pakistan: an analysis of provincial electronic immunization registry data," Vaccine, vol. 38, no. 45, pp. 7146-7155, 2020.

[2] T. Muthuprasad, S. Aiswarya, K. S. Aditya, and G. K. Jha, "Students' perception and preference for online education in India during COVID -19 pandemic," Social Sciences and Humanities Open, vol. 3, no. 1, Article ID 100101, 2021.

[3] A. R. Setiawan, "Scientific literacy worksheets for distance learning in the topic of Coronavirus 2019 (COVID-19)," EdArXiv, 2020.

[4] R. H. Huang, D. J. Liu, A. Tlili, J. F. Yang, and H. H. Wang, Handbook on facilitating flexible learning during educational disruption: The Chinese experience in maintaining undisrupted learning in COVID-19 Outbreak, Smart Learning Institute of Beijing Normal University, Beijing, China, 2020.

[5] AU Press, The Theory and Practice of Online Learning, T. Anderson, Ed., Athabasca University Press, Edmonton, AB, USA, 2008.

[6] S. Dhawan, "Online learning: a panacea in the time of COVID-19 crisis," Journal of Educational Technology Systems, vol. 49, no. 1, pp. 5-22, 2020.

[7] S. Bignoux and K. J. Sund, "Tutoring executives online: what drives perceived Quality?" Behaviour and Information Technology, vol. 37, no. 7, pp. 703-713, 2018.

[8] R. S. Huber, S. K. Sifers, D. Houlihan, and R. Youngblom, "Teacher support as a moderator of behavioral outcomes for youth exposed to stressful life events," Education Research International, vol. 2012, Article ID 130626, 10 pages, 2012.

[9] D. R. Garrison, T. Anderson, and W. Archer, "Critical thinking, cognitive presence, and computer conferencing in distance education," American Journal of Distance Education, vol. 15, no. 1, pp. 7-23, 2001.

[10] J. A. Baker, S. Grant, and L. Morlock, "The teacher-student relationship as a developmental context for children with internalizing or externalizing behavior problems," School Psychology Quarterly, vol. 23, no. 1, pp. 3-15, 2008.

[11] L. Henricsson and A.-M. Rydell, "Elementary school children with behavior problems: teacher-child relations and selfperception. A prospective study," Merrill-Palmer Quarterly, vol. 50, no. 2, pp. 111-138, 2004. 
[12] J. L. Spilled, J. N. Hughes, J. Y. Wu, and O. M. Kwok, "Dynamics of teacher- student relationships: stability and change across the elementary school and the influence on children's academic success," Child Development, vol. 83, no. 4, pp. 1180-1195, 2012.

[13] M. Adnan and K. Anwar, "Online learning amid the COVID19 pandemic: students' perspectives," Online Submission, vol. 2, no. 1, pp. 45-51, 2020.

[14] M. J. D. Adams and P. D. Umbach, "Nonresponse and online student evaluations of teaching: understanding the influence of salience, fatigue, and academic environments," Research in Higher Education, vol. 53, no. 5, pp. 576-591, 2012.

[15] I. Urquijo and E. Natalio, "Academic satisfaction at university: the relationship between emotional intelligence and academic engagement," Electronic Journal of Research in Educational Psychology, vol. 15, 2017.

[16] C. Muller, "The role of caring in the teacher-student relationship for at-risk students," Sociological Inquiry, vol. 71, no. 2, pp. 241-255, 2001.

[17] R. M. Ryan and E. L. Deci, "Intrinsic and extrinsic motivations: classic definitions and new directions," Contemporary Educational Psychology, vol. 25, no. 1, pp. 54-67, 2000.

[18] E. L. Deci, R. J. Vallerand, L. G. Pelletier, and R. M. Ryan, "Motivation and education: the self-determination perspective," Educational Psychologist, vol. 26, no. 3-4, pp. 325-346, 1991.

[19] R. J. Vallerand, “Deci and Ryan's self-determination theory: a view from the hierarchical model of intrinsic and extrinsic motivation," Psychological Inquiry, vol. 11, no. 4, pp. 312-318, 2000.

[20] D. Warner, G. Christie, and S. Choy, Readiness of VET Clients for Flexible Delivery Including Online Learning, Australian National Training Authority, Brisbane, Australia, 1998.

[21] M. McVay, "Developing a web-based distance student orientation to enhance student success in an online bachelor's degree completion program," Unpublished Practicum Report Presented to the Ed. D. Program, Nova Southeastern University, Fort Lauderdale-Davie, FL, USA, 2000.

[22] M. McVay, How to Be a Successful Distance Learning Student: Learning on the Internet, Pearson Custom Publishing, New York, NY, USA, 2001.

[23] P. J. Smith, "Learning preferences and readiness for online learning," Educational Psychology, vol. 25, no. 1, pp. 3-12, 2005.

[24] B. Lin and C. T. Hsieh, "Web-based teaching and learner control: a research review," Computers and Education, vol. 37, no. 3-4, pp. 377-386, 2001.

[25] E. L. Deci and R. M. Ryan, "The general causality orientations scale: self-determination in personality," Journal of Research in Personality, vol. 19, no. 2, pp. 109-134, 1985.

[26] A. J. Fairchild, S. J. Horst, S. J. Finney, and K. E. Barron, "Evaluating existing and new validity evidence for the Academic Motivation Scale," Contemporary Educational Psychology, vol. 30, no. 3, pp. 331-358, 2005.

[27] M.-L. Hung, C. Chou, C.-H. Chen, and Z.-Y. Own, "Learner readiness for online learning: scale development and student perceptions," Computers and Education, vol. 55, no. 3, pp. 1080-1090, 2010.

[28] A. R. Roper, "How students develop online learning skills," Educause Quarterly, vol. 30, no. 1, pp. 62-64, 2007.

[29] N. M. Alhajraf and A. M. Alasfour, "The impact of demographic and academic Characteristics of academic performance," International Business Research, vol. 7, no. 4, p. 92, 2014.
[30] A. Hay, M. Hodgkinson, J. W. Peltier, and W. A. Drago, "Interaction and virtual learning," Strategic Change, vol. 13, no. 4, pp. 193-204, 2004.

[31] A. G. Picciano, "Beyond student perceptions: issues of interaction, presence, and performance in an online course," Journal of Asynchronous Learning Networks, vol. 6, no. 1, pp. 21-40, 2002.

[32] K. Swan, "Virtual interaction: design factors affecting student satisfaction and perceived learning in asynchronous online courses," Distance Education, vol. 22, no. 2, pp. 306-331, 2001.

[33] R. Wagner, J. Werner, and R. Schramm, "An evaluation of student satisfaction with distance learning courses," in Annual Conference on Distance LearningUniversity of Wisconsin, Whitewater, WI, USA, 2002.

[34] B. Gilbert, "Online learning revealing the benefits and challenges," St. John Fisher College, Rochester, NY, USA, Education Masters, 2015.

[35] A. M. Remali, M. A. Ghazali, M. K. Kamaruddin, and T. Y. Kee, "Understanding academic performance based on demographic factors, motivation factors, and learning styles," International Journal of Asian Social Science, vol. 3, no. 9, pp. 1938-1951, 2013.

[36] A. Sun and X. Chen, "Online education and its effective practice: a research review," Journal of Information Technology Education, vol. 15, 2016.

[37] K. Frankola, "Why online learners drop out," WorkforceCosta Mesa, vol. 80, no. 10, pp. 52-61, 2001.

[38] K. Mukhtar, K. Javed, M. Arooj, and A. Sethi, "Advantages, Limitations and Recommendations for online learning during the COVID-19 pandemic era," Pakistan journal of medical sciences, vol. 36, p. S27, 2020.

[39] L. Y. Muilenburg and Z. L. Berge, "Student barriers to online learning: a factor analytic study," Distance Education, vol. 26, no. 1, pp. 29-48, 2005.

[40] L. A. Petrides, "Web-based technologies for distributed (or distance) learning: creating learning-centered educational experiences in the higher education classroom," International Journal of Instructional Media, vol. 29, no. 1, p. 69, 2002.

[41] G. Piccoli, R. Ahmad, and B. Ives, "Web-based virtual learning environments: a research framework and a preliminary assessment of effectiveness in basic IT skills training," MIS Quarterly, vol. 25, no. 4, pp. 401-426, 2001.

[42] S. Ryan, "Is online learning right for you?" American Agent and Broker, vol. 73, no. 6, pp. 54-58, 2001.

[43] S. Vonderwell, "An examination of asynchronous communication experiences and perspectives of students in an online course: a case study," The Internet and Higher Education, vol. 6, no. 1, pp. 77-90, 2003.

[44] N. Hara and R. Kling, "Students' frustrations with a webbased distance education course," First Monday, vol. 4, 1999.

[45] T. Nguyen, "The effectiveness of online learning: beyond no significant difference and future horizons," MERLOT Journal of Online Learning and Teaching, vol. 11, no. 2, pp. 309-319, 2015.

[46] C. Dziuban, P. Moskal, J. Thompson, L. Kramer, G. DeCantis, and A. Hermsdorfer, "Student satisfaction with online learning: is it a psychological contract?" Online Learning, vol. 19, no. 2, p. n2, 2015.

[47] A. E. Johnson, "A nursing faculty's transition to teaching online," Nursing Education Perspectives, vol. 29, no. 1, pp. 17-22, 2008.

[48] M. Ardeńska, A. Ardeńska, and R. Tomik, "Validity and reliability of the polish A version of the academic motivation scale: a measure of intrinsic and extrinsic motivation and 
amotivation," Health Psychology Report, vol. 7, pp. 254-266, 2019.

[49] J. R. Hayes, The Complete Problem Solver, Routledge, Oxfordshire, England, 2013.

[50] A. U. Rehman, "Challenges to online education in Pakistan during COVID-19 \& the way forward," AIJR Preprints, vol. 241, no. $1,2020$.

[51] K. Hartley and L. D. Bendixen, "Educational research in the Internet age: examining the role of individual characteristics," Educational Researcher, vol. 30, no. 9, pp. 22-26, 2001.

[52] L. Song and J. R. Hill, "A conceptual model for understanding self-directed learning in online environments," The Journal of Interactive Online Learning, vol. 6, no. 1, pp. 27-42, 2007.

[53] H. Snopce and S. Alija, "Student satisfaction, needs, learning outcome and motivation: a case study approach at A seeuniversity," The Eurasia Proceedings of Educational and Social Sciences, vol. 10, pp. 197-202, 2018.

[54] C. N. Gunawardena and F. J. Zittle, "Social presence as a predictor of satisfaction within a computer-mediated conferencing environment," American Journal of Distance Education, vol. 11, no. 3, pp. 8-26, 1997.

[55] C. Huggett, The Virtual Training Guidebook: How to Design, Deliver, and Implement Live Online Learning, American Society for Training and Development, Alexandria, VA, USA, 2014.

[56] N. Hara, "Student distress in a web-based distance education course," Information, Communication and Society, vol. 3, no. 4, pp. 557-579, 2000.

[57] J. R. Rourke, “Online learning: fad or fate?" Principal Leadership, vol. 1, no. 9, 2001.

[58] L. Schrum, "Online teaching and learning," in Distance Learning Technologies: Issues, Trends, and Opportunities, pp. 91-106, IGI Global, Hershey, PA, USA, 2000.

[59] L. Song, E. S. Singleton, J. R. Hill, and M. H. Koh, "Improving online learning: student perceptions of useful and challenging characteristics," The Internet and Higher Education, vol. 7, no. 1, pp. 59-70, 2004.

[60] E. M. Azila-Gbettor and M. K. Abiemo, "Moderating effect of perceived lecturer support on academic self-efficacy and study engagement: evidence from a Ghanaian University," Journal of Applied Research in Higher Education, vol. 13, no. 4, 2020.

[61] H. Lei, Y. Cui, and M. M. Chiu, "The relationship between teacher support and students' academic emotions: a metaanalysis," Frontiers in Psychology, vol. 8, Article ID 2288, 2018. 